\title{
Extração, embebição e germinação de sementes de tucumã (Astrocaryum aculeatum $)^{1}$
}

\author{
Sidney Alberto do Nascimento FERREIRA ${ }^{2}$ e Daniel Felipe de Oliveira GENTIL ${ }^{3}$
}

\begin{abstract}
RESUMO
A pesquisa teve como objetivo avaliar a influência da extração e da embebição das sementes sobre a germinação de tucumã (Astrocaryum aculeatum Meyer, Arecaceae). Após limpeza e secagem dos pirênios, o endocarpo foi quebrado e removido para liberação das sementes que, antes da semeadura, foram submetidas à embebição em água por 0, 3, 6, 9, 12 e 15 dias. A germinação foi superior a 58\%, independentemente do período de embebição, confirmando a possibilidade de retirar o endocarpo sem agravar prejuízos à viabilidade das sementes. As sementes submetidas a nove dias de embebição, com $30 \%$ de água, tiveram maior germinação (70\%) e índice de velocidade de germinação, com tempo médio de germinação de 104 dias. A remoção do endocarpo e a embebição das sementes aceleram e aumentam a germinação.
\end{abstract}

PALAVRAS-CHAVE

Palmeira, beneficiamento de sementes, dormência de sementes.

\section{Extraction, imbibition and germination of Astrocaryum aculeatum seeds}

\section{ABSTRACT}

The aim of this study was to evaluate the influence of the extraction and imbibition period on the germination of tucumã (Astrocaryum aculeatum Meyer, Arecaceae) seeds. After cleaning and drying the pyrenes, the endocarp was broken and removed to liberate the seeds that, before sowing, were soaked in water for $0,3,6,9,12$ and 15 days. The germination was superior to 58\%, confirming the possibility of extracting the endocarp without damaging the viability of the seeds. The seeds submitted to nine days of soaking, had a moisture content of $30 \%$, obtained better germination (70\%) and index of germination velocity, with mean time of germination of 104 days. The removal of the endocarp and the soaking of seeds accelerated and increased the germination.

\section{KEY WORDS}

Palm, seed processing, seed dormancy.

${ }^{1}$ Financiado pelo CNPq e pela FAPEAM.

${ }^{2}$ INPA-CPCA, Caixa Postal 478, 69011-970, Manaus/AM. E-mail: sanf@inpa.gov.br.

${ }^{3}$ UFAM - FCA, Av. Gal. Rodrigo 0. J. Ramos, 3000, Coroado I, 69077-000, Manaus/AM. E-mail: dfgentil@ufam.edu.br. 


\section{INTRODUÇÃO}

O tucumã (Astrocaryum aculeatum Meyer, Arecaceae), também conhecido como tucumã-do-amazonas ou tucumã-açu, é uma palmeira de crescimento monopodial, arborescente e monóica (Cavalcante, 1991). Parece ser nativo do Estado do Amazonas, onde é muito freqüente, sendo ainda encontrado nos estados brasileiros do Acre, Rondônia, Roraima, Pará e Mato Grosso, além das Guianas, Venezuela, Colômbia, Peru e Bolívia (Cavalcante, 1991; Kahn e Millán, 1992). Ocorre em floresta de terra firme, vegetação secundária (capoeiras), savanas, pastagens e roçados, sendo excepcionalmente tolerante a solos pobres e degradados (FAO, 1987). Em Manaus (AM), a exploração da polpa de tucumã e de seus derivados representa uma atividade econômica significativa e crescente no âmbito regional.

Embora o tucumã seja aparentemente pouco exigente quanto à fertilidade do solo e não apresente problemas fitossanitários, o seu cultivo na própria região amazônica é inexpressivo. Dentre os fatores que contribuem para essa situação estão, provavelmente, a dificuldade na germinação das sementes (Sá, 1984) e a impossibilidade da propagação vegetativa.

A dormência das sementes de tucumã pode estar relacionada, em parte, ao endocarpo pétreo que as envolve. Há indicações de que a cobertura protetora das sementes de algumas espécies pode dificultar a embebição de água, restringir a difusão de oxigênio e, ou, impor resistência mecânica ao crescimento do embriāo e à subseqüente emergência da plântula (Yocum, 1964; Popinigis, 1977).

$\mathrm{Na}$ produção de mudas de palmeiras, visando acelerar e uniformizar o processo germinativo de algumas espécies, tem sido recomendada a remoção completa das partes do fruto que envolvem as sementes (Yocum, 1964), como em Acrocomia mexicana, A. sclerocarpa (Koebernik, 1971), Attalea geraensis, A. phalerata, Butia archeri, B. capitata (Lorenzi, 1996) e Hyphaene thebaica (Moussa et al., 1998).

Outro procedimento é a imersão em água, que é indicado para as sementes de Copernicia spp. (Kitzke, 1958), Aiphanes erosa, Archontophoenix alexandrae, Areca lynn, Chrysalidocarpus lutescens, Dictyosperma aureum, Thrinax parviflora e Verschaffeltia splendida (Odetola, 1987). O período de imersão é variável entre as espécies, como três dias para Ptychosperma macarthuri, P. sanderianus (Odetola, 1987) e Hyphaene thebaica (Moussa et al., 1998), cinco dias para Arenga microcarpa, Phoenix acaulis e $P$. dactylifera (Odetola, 1987) e sete dias para Copernicia alba e Elaeis oleifera (Lorenzi, 1996). A troca diária da água é fundamental para evitar o aparecimento de limo, o apodrecimento das sementes e, ou, o desenvolvimento de microrganismos (Kitzke, 1958).

No caso das sementes de tucumã, apesar de serem sugeridas a retirada do endocarpo (Lorenzi, 1996) e a imersão em água por dois dias (Sá, 1984), não há informações sobre os métodos a serem empregados e suas conseqüências sobre as qualidades física e fisiológica dessas sementes. Diante disso, foi realizado o presente trabalho que teve como objetivo avaliar a influência da extração e da embebição em água na germinação das sementes dessa espécie.

\section{MATERIAL E MÉTODOS}

Este trabalho foi desenvolvido no Laboratório de Sementes e no Viveiro de Germinação da Coordenação de Pesquisas em Ciências Agronômicas (CPCA) do Instituto Nacional de Pesquisas da Amazônia (INPA), em Manaus (AM). Foi utilizado um lote de pirênios (sementes com endocarpo) de Astrocaryum aculeatum, resultante de uma mistura de progênies, adquirido numa feira de Manaus (AM), visando obter maior variação possível para a germinação, considerando que esta espécie apresenta indícios de ser alógama (Bacelar-Lima et al., 2003).

Inicialmente, os pirênios foram imersos em água por três dias, com a troca diária da água, a fim de facilitar a remoção dos resíduos de polpa aderidos ao endocarpo. A limpeza consistiu em fricção com areia, raspagem do endocarpo com faca e lavagem em água corrente. Em seguida, foi determinado o teor de água dos pirênios pelo método de estufa a $105 \pm 3^{\circ} \mathrm{C}$, por 24 horas (Brasil, 1992), utilizando quatro repetiçóes de cinco unidades. Os pirênios restantes foram postos a secar, em ambiente com temperatura média de $28^{\circ} \mathrm{C}$ e umidade relativa do ar média de $65 \%$, até que a maioria das sementes se soltasse dentro do endocarpo, verificado pela movimentação dos pirênios. Durante a secagem, foi realizado o monitoramento diário da perda de massa dos pirênios (19 amostras de 50 pirênios), que serviu para estimar o teor de água dos mesmos, ao longo de todo o período de observação, baseado no grau de umidade inicial. Depois disso, as amostras foram misturadas e procedeu-se à quebra do endocarpo, com o auxílio de um martelo, uma tira de borracha e um cepo de madeira: o pirênio, envolto pela tira de borracha, foi posicionado sobre o cepo e, com o martelo, foi dada uma pancada, de modo a partir ou trincar o endocarpo com um só golpe, obtendo-se assim a semente. $\mathrm{O}$ processo de extração, realizado por três pessoas, foi avaliado tanto em relação ao rendimento (número de sementes extraídas/hora/homem) quanto ao estado das sementes extraídas (porcentagem de sementes fisicamente íntegras, de sementes com danos mecânicos visíveis, de sementes podres e de sementes geminadas). Logo em seguida, foi determinado o teor de água das sementes fisicamente íntegras (quatro repetições de cinco sementes) a $105 \pm 3^{\circ} \mathrm{C}$, por 24 horas, conforme Brasil (1992).

As sementes fisicamente íntegras obtidas foram misturadas $\mathrm{e}$ imersas em água, com a substituição diária da água, quando então se passou a monitorar diariamente o aumento de massa em quatro amostras de 10 sementes. A partir do teor de água inicial, estimou-se o grau de umidade das sementes ao longo de todo o período de embebição. Após 0, 3, 6, 9, 12 e 15 dias de embebição, 
quatro subamostras de 25 sementes foram semeadas em substrato areia e serragem (relação volumétrica de 1:1) e mantidas em viveiro coberto com telha de fibra de vidro transparente (temperatura do ar média mínima de $24^{\circ} \mathrm{C}$ e máxima de $38^{\circ} \mathrm{C}$ ). Na semeadura, as sementes foram posicionadas, sob uma camada de $1 \mathrm{~cm}$ de substrato, com o opérculo formando um ângulo de $45^{\circ} \mathrm{em}$ relação a um eixo imaginário perpendicular ao nível do substrato.

A avaliação da germinação foi realizada a cada 10 dias, até 210 dias da semeadura, com a contagem das sementes que apresentavam o intumescimento do "pecíolo cotiledonar", formando uma estrutura denominada "botão germinativo" (Tomlinson, 1990). A partir desses dados, foram calculados a porcentagem, o índice de velocidade (Maguire, 1962) e o tempo médio de germinação (Edwards, 1934). No encerramento do experimento, aplicando o teste de corte nas sementes não germinadas (Brasil, 1992), foram computados os números de sementes dormentes (sementes com embriōes firmes, sadios e de coloração branco-leitosa) e de sementes mortas (sementes com embriōes deteriorados).

O delineamento experimental utilizado foi o inteiramente casualizado, empregando seis tratamentos $(0,3,6,9,12$ e 15 dias de embebição), com quatro repetiçóes. $\mathrm{Na}$ análise estatística, os dados de porcentagem de germinação foram transformados em arco seno raiz quadrada de $\mathrm{x} / 100$ e os de porcentagem de sementes dormentes e de sementes mortas em raiz quadrada de $\mathrm{x}+0,5$. Os dados foram analisados pelo estudo de regressão.

\section{RESULTADOS E DISCUSSÃO}

O processo de secagem dos pirênios, até o desprendimento interno das sementes no endocarpo, foi lento (Figura 1a), tendo a maioria das sementes se soltado aos 30 dias. Neste momento, os pirênios apresentaram redução no teor de água de $9 \%$, passando de $23 \%$ (inicial) para 14\% de água (final).

Com a quebra do endocarpo, obteve-se o aproveitamento de $79,6 \%$ de sementes aparentemente sem danos (fisicamente íntegras), além de $19 \%$ de sementes com algum tipo de dano visível, $1 \%$ de sementes com sintomas de apodrecimento e $0,4 \%$ de sementes geminadas (duas sementes por pirênio). $\mathrm{O}$ rendimento foi de 377 sementes extraídas/hora/homem. A retirada do endocarpo rígido de sementes de palmeiras sempre apresenta riscos de danos ao endosperma e ao embriáo, sendo que para algumas espécies, como Maximiliana regia, esse procedimento foi prejudicial às sementes (Martins et al., 1996).

O percentual de sementes de tucumã danificadas foi considerado elevado, apesar dos cuidados em quebrar o endocarpo com apenas uma pancada, já que o aumento do número de golpes implicaria no aumento do risco de danificações. Diante disso, sugere-se avaliar, em estudos posteriores, a dessecação em ambiente com menor umidade relativa do ar e, ou, com ventilação forçada, a fim de diminuir o período de secagem para a extração. Ademais, é possível que a maior redução no teor de água dos pirênios aumente o percentual de sementes extraídas sem injúrias mecânicas.

A embebição das sementes, até apresentar aumento no teor de água proporcional ao que foi perdido na secagem dos pirênios, ocorreu em menor tempo (Figura $1 \mathrm{~b}$ ), devido provavelmente à ausência do endocarpo. No decorrer de 15 dias de embebição, houve o aumento de $11 \%$ no teor de água das sementes, passando de 20\% (inicial) para 31\% de água (final).

A porcentagem de germinação, que nas sementes não embebidas foi de $58 \%$, aumentou progressivamente até alcançar o valor máximo de $70 \%$ nas sementes submetidas a nove dias de embebição (Figura 2), momento em que o grau de umidade foi de $30 \%$ (Figura 1b). A partir disso, a germinação decresceu até 64\% nas sementes submetidas a 15 dias de embebição.

A elevada porcentagem de sementes mortas (em torno de $26 \%$ ), variável que não foi afetada pelos diferentes períodos de embebição (Figura 2), pode ter sido, em parte, decorrente de danos provocados pelo método de extração, os quais não foram visualizados antes da semeadura. Considerando o aproveitamento de cerca de $80 \%$ de sementes extraídas sem danos aparentes e o percentual máximo de germinação atingido (Figura 2), o rendimento efetivo foi de $56 \%$ de sementes germinadas. Isso confirma a necessidade de aperfeiçoamento do método de extração, visando inclusive a redução do número de sementes
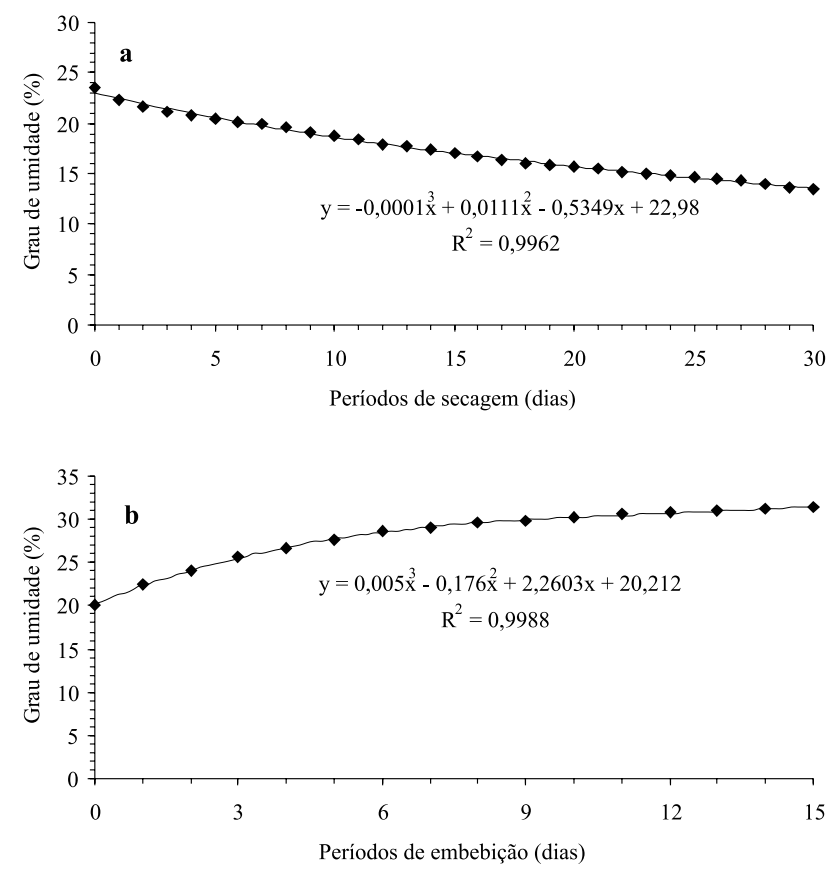

Figura 1. Graus de umidade estimados durante a secagem dos pirênios (a) e durante a embebição das sementes (b) de tucumã (Astrocaryum aculeatum). 
que apodrecem na sementeira, devido possivelmente às injúrias provocadas pela quebra e remoção do endocarpo.

$\mathrm{O}$ índice de velocidade de germinação apresentou comportamento semelhante à germinação (Figura 2). O valor, que foi baixo com zero dias de embebição, aumentou até nove dias e, posteriormente, decresceu até 15 dias de embebição.

$\mathrm{O}$ tempo médio de germinação decresceu à medida que aumentou o período de embebição (Figura 2), sendo que para cada dia de embebição houve a redução de um dia no tempo médio de germinação. Nas sementes embebidas por nove dias, que tiveram os maiores valores de germinação e do índice de velocidade de germinação, o tempo médio de germinação foi de 104 dias. De qualquer modo, levando-se em conta o tempo médio ainda elevado, sugere-se que a dormência das sementes de tucumã não está relacionada somente ao endocarpo, mas também a outros fatores ainda desconhecidos.

Baseado na literatura, o período de germinação das sementes de tucumã, com endocarpo, pode se estender por dois (Sá, 1984) a três anos (Koebernik, 1971). No presente trabalho, o tempo médio de germinação foi de 104 dias, sugerindo que a retirada do endocarpo favoreceu a redução desse período. Contudo, a germinação desuniforme e a porcentagem de sementes dormentes (Figura 2) indicaram que outros fatores também limitam a capacidade germinativa dessas sementes. Ademais, a distribuição da germinação no período de quatro meses, entre a primeira (41 dias, em média) e a última (164 dias, em média) contagem das sementes germinadas, independentemente do período de embebição, evidenciou a existência de uma graduação na intensidade de dormência.

Nas sementes não embebidas, além da porcentagem de germinação ter sido inferior, o processo germinativo foi mais lento, o que é confirmado pelo menor índice de velocidade de germinação e maior tempo médio de germinação (Figura 2). A embebição, antes da semeadura, pode favorecer a velocidade de germinação de sementes, visto que a absorção de água representa o passo inicial do processo germinativo. Em tucumã, este efeito benéfico foi mais pronunciado nas sementes submetidas à embebição por nove dias, sendo por isso recomendado como tratamento pré-germinativo das sementes dessa espécie.

\section{CONCLUSÃO}

A remoção do endocarpo e a embebição das sementes aceleram e aumentam a germinação de tucumã.

\section{BIBLIOGRAFIA CITADA}

Bacelar-Lima, C.G.; Coletto-Silva, A.; Gribel, R. 2003. Biologia floral e visitantes de Astrocaryum aculeatum Meyer (Arecaceae) em Manaus, AM, Brasil. In: CONGRESSO NACIONAL DE BOTÂNICA, 54., Belém, 2003. Resumos. Belém: UFRA/MPEG/ EMBRAPA Amazônia Oriental.

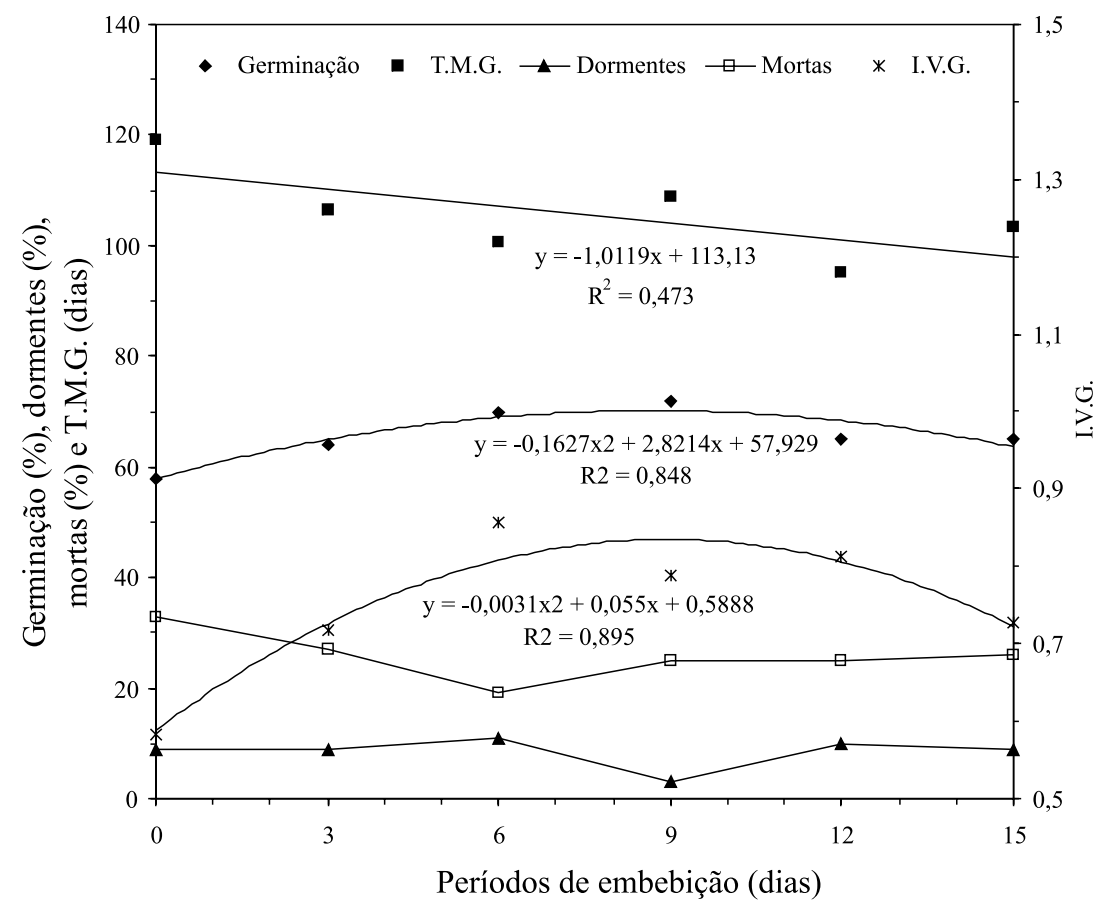

Figura 2. Germinação, índice de velocidade de germinação (I.V.G.), tempo médio de germinação (T.M.G.), sementes dormentes e sementes mortas, referentes a sementes de tucumã (Astrocaryum aculeatum) submetidas a diferentes períodos de embebição. 


\section{ACTA}

Brasil. 1992. Ministério da Agricultura e Reforma Agrária. Regras para análise de sementes. Brasília: CLAV/DNDV/SNAD/MA. 365pp.

Cavalcante, P.B. 1991. Frutas comestiveis da Amazônia. 5.ed. Belém: Edições CEJUP/Museu Paraense Emílio Goeldi. 279pp. (Coleção Adolfo Ducke).

Edwards, T.I. 1934. Relations of germinating soy beans to temperature and length of incubations time. Plant Physiology 9(1): $1-30$.

FAO. 1987. Especies forestales productoras de frutas y otros alimentos. 3. Ejemplos de America Latina, 44/3. Rome: FAO. 241pp.

Kahn, F.; Millán, B. 1992. Astrocaryum (Palmae) in Amazonia: a preliminary treatment. Bulletin Institute Français d'Étude Andines, 21(2): 459-531.

Kitzke, E.D. 1958. A method for germinating Copernicia palm seeds. Principes, 2(1):5-8.

Koebernik, J. 1971. Germination of palm seed. Principes, 15(4): 134-137.

Lorenzi, H. (Coord.) 1996. Palmeiras no Brasil: exóticas e nativas. Nova Odessa: Plantarum. 303pp.

Maguire, J.D. 1962. Speed of germination: aid in selection and evaluation for seedling emergence and vigour. Crop Science, 2(2): 176-177.
Martins, C.C.; Silva, W.R.; Bovi, M.L.A. 1996. Tratamentos prégerminativos de sementes da palmeira inajá. Bragantia, 55(1): 123-128.

Moussa, H.; Margolis, H.A.; Dubé, P.A.; Odongo, J. 1998. Factors affecting the germination of doum palm (Hyphaene thebaica Mart.) seeds from the semi-arid zone of Niger, West Africa. Forest Ecology and Management, 104: 27-41.

Odetola, J.A. 1987. Studies on seed dormancy, viability, and germination in ornamental palms. Principes, 31(1): 24-30.

Popinigis, F. 1977. Fisiologia de sementes. Brasília: AGIPLAN. 289pp.

Sá, S.T.V. 1984. Superação da dormência de sementes de tucumã (Astrocaryum tucuma Mart.). Manaus. 53f. Monografia (Graduação Engenheiro Agrônomo), Departamento de Ciências Agrárias, Universidade do Amazonas.

Tomlinson, P.B. 1990. The structural biology of palms. Clarendon Press. Oxford. 477pp.

Yocum, H.G. 1964. Factors affecting the germination of palm seeds. The American Horticultural Magazine, 43(2): 104-106.

Recebido em 17/08/2005

Aceito em 07/02/2006 